\title{
ON BECOMING A BETTER SUPERVISOR: A DECONSTRUCTION OF AUTOETHNOGRAPHY AS METHOD FOR PROFESSIONAL DEVELOPMENT
}

\author{
S. M. O'Neil
}

Department Human Resource Management

University of Pretoria

Pretoria, South Africa

e-mail: sumari.oneil@up.ac.za

\section{ABSTRACT}

Although not often applied, the autoethnographic method lends itself for use in professional development practices. The literature contains a few examples in which autoethnography is used for this purpose, but with the focus solely on the relationship between mentee and mentor that creates the space for professional development to occur. In the current study, I explored, through a reflective account, the possibilities for using analytic autoethnography for professional development by drawing on the theory of transformative learning. Although there are some drawbacks in using autoethnography, the method may be a valuable addition to current professional development tools if used by the individual practitioner.

Keywords: analytic autoethnography, creative analytic practices, critical reflection, evocative autoethnography, postgraduate research supervision, reflective practice, transformative learning

\section{ORIENTATION}

Professional development is seen to play a critical role in ensuring the quality of teaching and learning in universities today (De Rijdt et al. 2013). Especially in the currently rapidly changing higher education contexts, professional development is often viewed as the panacea to problems (Behari-Leak 2017), as it is supposed to relate to envisaged changes in the organisation at large. Professional development efforts should translate to changes in the way a professional thinks and behaves and increase the effectiveness of obtaining institutional goals.

Although the focus of professional development is on the change in practice, in other words, the transformative quality thereof, it unfortunately often remains a one-time affair for which a certificate can be shown, but to which little change relates in practice (Behari-Leak 2017). Some of the reasons for the lack of transformative power of the professional development attempts are that they are not contextualised with the unique challenges and needs related to the individual professional (Lueddeke 2003).

Research methods such as action research are well known for their professional 
development properties (McNiff 1995; Kennedy 2005). Autoethnography on the other hand is less well known in this domain. Autoethnography is a qualitative method where the researcher, write (or do research) about the self in order to understand the context and culture of that which is being studied (Adams et al. 2015). It uses a systematic approach to collect, analyse and interpret data about the self, the environment and possibly others (Ngunjiri, Hernandez and Chang 2010).

Over the past couple of years there has been a growth in the publication and application of autoethnography to many fields, including higher education (Learmonth and Humphreys 2011; Tillman 2011; Van Amsterdam 2014). Despite gaining much ground in the past decades to become an established qualitative inquiry method (Adams et al. 2015), there are only a few published examples of autoethnography being used explicitly in a professional development context (see Chang, Longman and Fanco 2014; Grenier and Collins 2016; Kempster and IszattWhite 2012; Kinchin and Cabot 2015). Kempster and Iszatt-White (2012) introduced coconstructed autoethnography as a form of leadership development. Similar to the process when constructing a co-constructed autoethnography for research purposes, the developmental process begins with the mentee (or student) writing a narrative about his or her leadership experiences. The narrative is then interrogated by a mentor or coach. Critical reflection on the narratives is facilitated by the relationship and critical dialogue between mentor and mentee. Similarly, Chang et al. $(2014,386)$ note the unexpected leadership development that occurred in mentoring relationships when mentee and mentor engaged in collaborative autoethnography:

"Although we did not begin with collaborative autoethnographic research as an action to solve an identified problem, the process provided us an opportunity to engage in scholarly endeavours at a very human level that enriched our lives personally and strengthened us professionally."

Facilitated autoethnography is proposed by Grenier and Collins (2016) for use in human resource development practices. In facilitated autoethnography the co-constructer takes the role of a facilitator who through probing and guidance supports the story-teller (also referred to as the lead) in creating a story. In the process of storytelling, reflection and guidance, the opportunity is created for development in one's practice.

Kinchin and Cabot (2015), who focussed on the development of university lecturers, also used a co-constructor to collaborate and guide the process of autoethnography. Because of the unstructured nature of autoethnography, the process of finalising the stories of the self may be time-consuming. To address this limitation of autoethnography for the purpose of professional development, they used co-constructed concept maps as elicitation techniques to focus the stories of the self. Kinchin and Cabot (2015) refer to their technique as framed autoethnography. 
Framed autoethnography takes place in an interview setting during which the interviewee is prompted to reflect on personal stories about his or her pedagogy. The autoethnography is therefore in essence also co-constructed during a facilitated reflection process.

Although the processes of using autoethnography for professional developmental differ between Kinchin and Cabot (2015), Chang et al. (2014), Kempster and Iszatt-White (2012) and Grenier and Collins (2016), the interaction between mentor and mentee or interviewer or interviewee is seen as the main contributing factor of the method that facilitates professional development. For all of the methods described, although they focus on the exploration of the professional experiences of one individual and therefore not collaborative autoethnography in the traditional sense as described by Chang, Ngunjiri and Hernandez (2013), the professional development takes place in dialogue with someone else who guides the process (Blalock and Akehi 2017). Therefore, co-constructed, collaborative and framed autoethnography could be nested within the coaching/mentoring model of professional development as proposed by Kennedy (2005), in which the coaching or mentoring relationship facilitates learning and transformation.

In this article I propose that a different form of autoethnography, namely analytic autoethnography, can be used as a tool for professional development of academic lecturing staff at universities. The exploration of the self in analytic autoethnography does not require the researcher to be guided by another person. I offer a description of how analytic autoethnography transformed my own practice and understanding of being a postgraduate research supervisor. I argue that essentially, professional development should contain elements of transformative learning. Therefore, if a method such as autoethnography leads to transformative learning in one's own practices, it may be used for professional development purposes.

\section{THEORETICAL FRAMEWORK: PROFESSIONAL DEVELOPMENT AND TRANSFORMATIVE LEARNING}

Professional development includes any activities that strengthen and extend knowledge, skills and conceptions of professionals within their practice (De Rijdt et al. 2013). Although the definitions of professional development differ between contexts, they all have two characteristics in common: firstly, that it involves the education of adults, and secondly, that it should produce a positive change in beliefs, knowledge, skills and behaviours (Lauer et al. 2014). Accordingly it should be capacity-building processes that "build on critical reflection, and participatory, action and transformative learning pedagogical strategies" (Mulà et al. 2017, 805). In this article I focussed on the transformative learning pedagogy, as it includes critical reflection (albeit in one's perspective), participation in critical reflective dialogues, and action 
during the process of perspective shift.

Reflection plays a critical role in professional development as defined by Mulà et al. (2017) and also has a key role to play in transformative learning as can be seen in the theories of Dewey (1933), Habermas (1971), Schön (1983) and more recently Moon (1999). According to Mezirow's (1991) transformative learning theory, critical reflection is one of the key activities, along with shared discourse through dialogue that may lead to cognitive dissonance, a change in one's frame of reference or transformations of one's habits of mind (Becker 2017). The outcome of transformative learning is change not only within a cognitive, but also emotional paradigm (Boyd 2008).

Mezirow developed a ten-stage process of transformative learning (Botha 2010; SprowForte and Blouin 2016). According to the process, learning starts with a disorienting dilemma that leads to the process of reflection on one's current beliefs, practices and actions (Boyd 2008). During this process there is a realisation of discontent with one's own perspectives that is reached through critical dialogue. Discontent is not only on a cognitive level, but reflections on previously held perspectives leave one with shame, guilt or embarrassment. Owing to the discontent, one will be propelled into exploring and experimenting with new roles and plan a course of action in taking up the roles; that is, to acquire the needed knowledge and skills to fulfil the new role. In fulfilling the new role, one builds confidence and competence in action. The final stage and ultimate goal in the transformative learning process is to reintegrate the new perspective into one's life. The process or stages one follows to achieve transformation, according to Mezirow's theory, need not be followed in a chronological order; rather, it can be an iterative process with many variations (Hoggan 2016).

In 2010, I embarked on a study in which I used analytic autoethnography to explore more effective supervision practices for master's mini-dissertation students. After completion of the study, I realised how the autoethnographic journey changed my professional practice as supervisor. In the current study I placed my experiences of conducting analytic autoethnography alongside the stages of learning (and transformation) developed by Mezirow (1991; 1996; 1997; 2000). I did this in an effort to illustrate how development and transformation took place in my supervision practice. Therefore, this article reports on a critical reflection and analysis of how analytic autoethnography as a tool can aid in supervisor development. In the following section I describe my autoethnographic study in order to give the reader the necessary background to understand the application of this process to transformative learning and professional development, which is presented later in the article. 


\section{MY AUTOETHNOGRAPHIC STUDY}

Autoethnographic methods, as we understand them today, have their roots as far back as 1935 (Hayano 1979), and have since been called by different names and described with many variations (Adams et al. 2015; Chang 2008). Although it is different from other self-narrative methodologies, autoethnography in itself has many variations of application. It may include anything from a study focussing on the self (see Pelias 2003), to inquiring into groups of which the researcher is part (see Ngujiri Hernandez and Chang 2010), or extending the inquiry to other groups of which the researcher is not part but through the method of inquiry becomes a cocreator in recreating the stories (see Ellis and Rawicki 2013; Rawicki and Ellis 2010). My autoethnography focussed on my own experiences as supervisor, as well as the experiences of the group of mini-dissertation supervisors, and also the mini-dissertation student whom I supervised from 2008 to 2015.

I chose to use an autoethnographic approach above methods such as action research. Although both the methodologies rely on reflection on own practice, autoethnography allows for deep insights into experiences not always possible in other methodologies (Ngunjiri, Hernandez and Chang 2010). These deep insights evolve out of continuous reflection on one's own story. The reflection is furthermore facilitated by the process of narrative writing (writing about one's life and experiences), which is inherent to the autoethnographic method. The mere act of writing becomes an act of reflection in itself, while generating data for analysis.

Using autoethnographic methods allows one also to draw links between one's own experiences and the culture in which the experiences are embedded. Because the researcher is an insider, the autoethnographic inquiry enables not only a deep understanding of the researcher himself or herself, but also of the culture in which he or she is embedded and the interaction between the researcher and the culture (Cunningham and Jones 2005; Gearity and Mertz 2012; Wall 2006). The researcher can "draw on personal experiences, cultural competence and linguistic resources to frame and shape research in a way that an outsider cannot" (Karra and Phillips 2008, 547).

For my study, I decided to use analytic autoethnography rather than its counterpart, evocative autoethnography. Analytic autoethnography implies five things: 1) the researcher is a complete member researcher (CMR), 2) analytic reflexivity is used during the study, 3) the researcher is visible and active in the text, 4) there is dialogue with informants beyond the self, and 5) there is a commitment to theoretical analysis (Anderson 2006).

Being a CMR implies the ultimate participant in a dual participant-observer role. In comparison with other researcher roles, being a CMR is the closest observer one can get as he or she can approximate the emotional stance and setting most accurately. Analytic reflexivity implies the researcher actively reflects on his or her connection to the research situation, and 
their effect on it. This self-conscious introspection is guided by a desire to better understand both himself or herself and others in the context of the study by actively examining his or her actions and perceptions in reference to the study, the participants and the context.

Anderson (2006) explains that every insight gained in the reflexive stance is a doorway to how "others" in the culture experience the phenomenon, as well as how the researcher himself or herself experienced it. He refers to it as reflexive social analysis and reflexive self-analysis. The overall aim is to seek connections between that which the researcher experiences and feels to the broader context or theory.

The researcher should also be visible and active as a social actor in the text by incorporating the researcher's own feelings and experiences into the story (or report). This is considered to be vital data for understanding the social world being observed.

According to Anderson (2006) one do not use only one's own experiences in one's autoethnography, but also ask other people about their experience in order to draw connections between own experiences and the broader context. However, "[t]he necessity, value, and feasibility of such [other data sources] will vary according to the specifics of a given project and the goals of its creator(s)" (Vryan 2006, 406).

All of the points above may also be present in other more evocative forms of autoethnography. The only real difference between evocative and analytic autoethnography is the conscious and explicit commitment of analytic autoethnography to theoretical analysis. This is in opposition to evocative autoethnography where the overall aim is to evoke an emotional response from the reader (DeBerry-Spence 2010). Although evoking responses is not necessarily excluded in analytic autoethnography, its focus is on explicit analysis and the development of conceptual and theoretical models from the analysis of personal data (Vryan 2006).

For my autoethnography of postgraduate research supervision I used explicit analysis and a systematic method of data collection, but I also used evocative and creative analytic practices (CAP) to display my findings. These included several short stories on my experiences as an academic and supervisor, as well as illustrated short stories. Music and photographs were also part of the display of results to illustrate emotions or the setting in which the experiences took place. Illustrations 1-3 are examples of CAP in my autoethnography.

Illustration 1 shows an example of the use of photographs to link my story to the context (in the case of my study, my workplace). Illustration 2 is an example of fictional writing and the use of music in my autoethnography. This particular excerpt shows my sense-making of the difference between analytic and evocative autoethnography in accordance to the academic argument in the 2006 edition of the Journal of Contemporary Ethnography. The music was added to the manuscript in mp3 (Motion Picture Experts Group Layer-3 sound file) format. 
I know that much of my preoccupation with autoethnography can be related back to the reservations my colleagues have about it. On countless occasions when we meet in the hallway or in our office building and when the conversation turns to my doctorate it's about having decided to use an autoethnographic approach.

"What exactly is it?" they ask, as I become aware of the critical and doubtful expressions on their faces. No matter how I try to explain, their frowns only deepen and I see the scepticism in their eyes. The general polite reply is always: "Interesting, but are you sure this is what you want to do?."

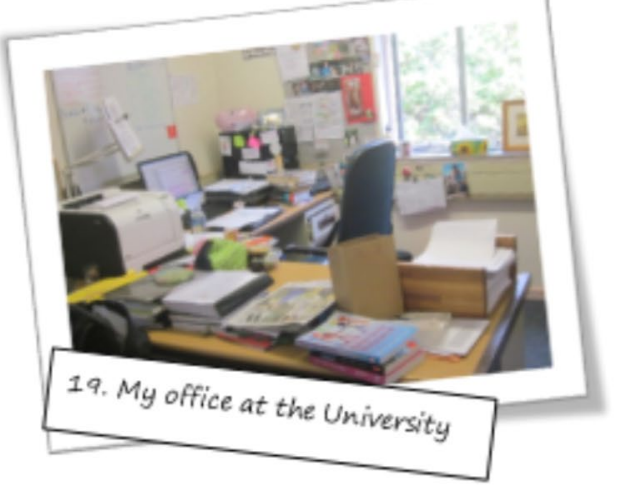

I sigh as I think that they don't have the faintest idea what autoethnography is about and, worse, they can't understand why anyone in their right mind would use it in

Illustration 1: Excerpt of a page from my PhD showing how photographs were used to display the setting of the study (O'Neil 2016, 61)

In my mind's eye, I see a woman with wavy red hair tied back from of her face with a scarf tied gypsy style. Her lips are red and her dress is colourful ... as she comes closer I can see that the dress is not made of material, but of photographs of herself stitched together artistically. I have never seen anything like it before and I am drawn to her. She is bohemian and avant-garde. I instinctively know that she is CAP.

There is another figure in the room. It is a man; a proper English gentleman. He is measuring something. The concentration needed to do it perfectly is visible on his face.

The woman notices the man. From where I sit I can see that they look alike - could have been twins. The woman does not seem to like the man. She takes one look at him and starts singing phrases out of what I recognise as the English translation ${ }^{1}$ of Jacques Brel's Less Bigotes ${ }^{1}$ (Little hypocrites) ( $\#$ 5). "They never sing, they never dance. They'll never get another chance. Little hypocrites! Oh they grow old without a song, for they've been old their whole lives long! Little hypocrites!"

The man looks amused and responds with woof\}; Who let the dogs out \{woof, woof, woof, woof $\}$, see ya' little speed boat head up our coast, She really wants to skip town; Get back scruffy, back scruffy, Get back u flea infested mongrel!" and then in a thick English accent staring out in front of him says, "It's a spectacle I say, an absolute spectacle!" He continues with his measurements.

...The woman smiles as he walks away and climbs onto the table. She sings triumphantly 7): “I don't give a damn 'bout my reputation, You're living in the past it's a new generation. A girl can do what she wants to do and that's what I'm gonna do. And I don't give a damn 'bout my bad reputation ... I've never been afraid of any deviation. An' I don't really care If I'm strange. I ain't gonna change, an' I'm never gonna care, 'bout my bad reputation. Oh no, not me1."

Illustration 2: Excerpt of a vignette showing how music and short fictional stories were used (O’Neil 2016, 90-91) 
They played together until the sun set, and only then, when the stars looked down on them, they fell asleep. Thombi was Curled up safely and comfortably in the dragon's huge paw.

Finally, Thombi's nightmare was over. She had conquered all her worst fears and was successful in her quest for her own dragon.
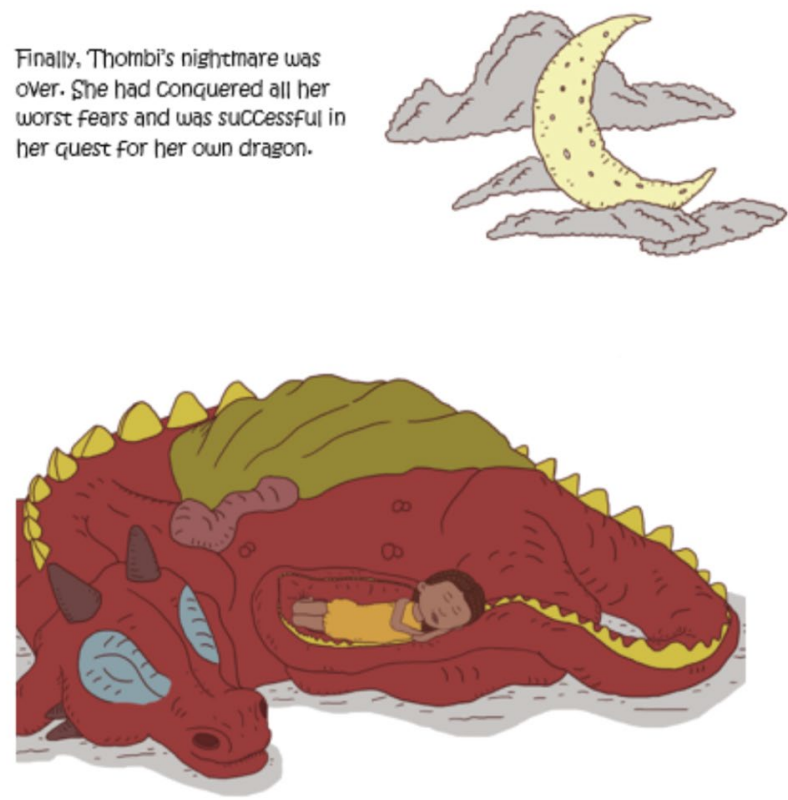

She drearned the sweetest dreams of her return to her Village, and she knew that from that day onward she and the rainbow dragon would be the best of friends and for many years to come would be the champions of Thutong.

Illustration 3: Excerpt from an illustrated fantasy story, “Catching a dragon” (O'Neil 2016, 371)

Illustration 3 is a page from the illustrated fantasy story for children. The story is about a little girl, Thombi, who lives in a village, Thutong. All adult Thutongians have dragons which they parade with to show off their bravery. The story is about Thombi who goes out alone into the wilderness to search for and catch her own dragon, in order to become a worthy member of the Thutong clan. The story was written to illustrate my own struggles, as an academic, to complete my $\mathrm{PhD}$ study and in doing so completing the first step in becoming a scholar.

Owing to the nature of qualitative inquiry, the focus was on exploring my lived experiences and participant-defined meanings of supervising master's mini-dissertation students within the context of higher education in South Africa (Sergi and Hallin 2011; Willig 2013). Although the focus in autoethnography is on the researchers' own experience, one may also use experiences of other actors in the context. In the case of my study, I used the experiences of my students as well as other mini-dissertation supervisors to deepen my understanding of the context as well as my own supervision choices.

Data collection in autoethnographic studies can take various forms, such as reflective journals (Holt 2003), e-mails, memos, and sketches (Duncan 2004). Data can be textual and non-textual (Chang 2008; Muncey 2005). For the most part, autoethnographers have used the same data sources, namely field notes, personal documents and interviews (Anderson and Glass-Coffin 2013). 
I used both hard and soft data in different forms for my study, including self-observational, self-reflective and external data (Chang 2008). The external data consisted of stories from the other supervisors and my students gathered by means of interactive interviews (Ellis and Bochner 2000), informal conversations (McIlveen et al. 2010) and e-mail conversations (Gearity and Mertz 2012). Data from my own experiences consisted of self-reflections and reflective writing on my supervision experiences.

\section{AUTOETHNOGRAPHY AS A TRANSFORMATIVE JOURNEY}

Boyd (2008) describes how autoethnography led to transformative learning on the impact of his whiteness on his behaviour, language and attitudes. The pattern of introspection he followed is based on Mezirow's process of transformative learning, in which one first recognises that different perspectives can provide new insights into solving a particular problem; then one becomes aware of the sources, context, and the consequences of the former perspective. Next, one engages in critical reflection on one's existing assumptions, subsequently validating the new perspective or beliefs by testing them in action. Lastly, one changes one's behaviour or worldview on the basis of one's newly adopted perspectives. In this section, I will illustrate how the same phases are discernible in my own autoethnographic journey.

\section{The dilemma of my supervision}

"If I look at a lot of the students that's done their research under my supervision, it is just as though I can't get them out of that ... you know, in the momentum to complete ... and I can't understand that black hole. Where are you now? I can't pull them out of there. [For a student] it's an abyss that she finds herself in. And, I don't know how to get her out of it."

(My "confession" at a group supervision session early in 2010. This was part of the data for my autoethnography.)

As a supervisor, I realised early on that I was failing to fulfil the ever-growing needs of my students who faced challenges that were not directly related to the content of their dissertations, but were caused by the concomitant feelings of being lost and alone.

When I started supervising I had no idea how complex it really was. With reason, I found out later why scholars like Vilkinas (2002) describe supervision as complex and challenging. As a novice supervisor I was ill prepared, and started out supervising the only way I knew: a dyadic relationship between the supervisor and student, setting out the structure of the dissertation, then waiting for the student to work within that structure and giving feedback along the way. This was not only the way in which I had been supervised but also how everyone else in my department supervised their students. 


\section{Discontent and shame with my perspectives}

"When I started supervising, it did not even cross my mind that I would not be good at it. Because of my experience in practice as a research psychologist, I thought I would be able to discuss and conceptualise the research problems with the students, give direction on how the study needed to be conducted and give feedback to assure the quality of the product along the way. Thinking back now, I do not know which planet I was coming from. When reality struck me, I very quickly realised it would be more difficult than I expected. There were two particular challenges: firstly, I could not cope with the emotional rollercoaster the students were on when completing their dissertations, and secondly, the one-on-one supervision was not sufficiently providing social learning opportunities for students to engage in." (Excerpt from my autoethnography) (O'Neil 2016, 260).

In 2007 I realised that my supervision was not adequate. Although none of my students were failing, I felt as though I was failing them. I felt sorry for my students when I realised that they were struggling with the emotional side of their journey, but most of the time I had no idea what they were going through.

The shortcoming in my supervision can be illuminated by referring to Anderson, Day and McLaughlin's definition of supervision (2006). According to them, supervision for master's coursework students can be seen as a duality of supporting and shaping (see Figure 1). On the one hand, the supervision should be aimed at shaping the dissertation in such a way that it meets the quality criteria, with shaping taking place at an academic and cognitive level of supervision. On the other hand, the supervisor also has a supporting function, which for Anderson et al. (2006) revolves around supporting a sense of agency in the student and includes all the actions needed to assist the student in pursuing a topic of personal interest and scaffolding the student's sense of agency. For me, however, the support function also lies at a deep psychological and emotional level and involves managing the students' fears, breaking the isolation in which the students operate, and giving them a sense of balance to deal with the various demands on their lives, such as work, dissertation and family, to name but a few aspects.

\section{An exploration of new roles}

In light of the challenges I faced, combined with the inherent vulnerabilities of one-on-one supervision and the opportunities of a more collective supervision practice I considered forms of group supervision (Bitzer and Albertyn 2011; Conrad 2003; Lee and Green 2009). 


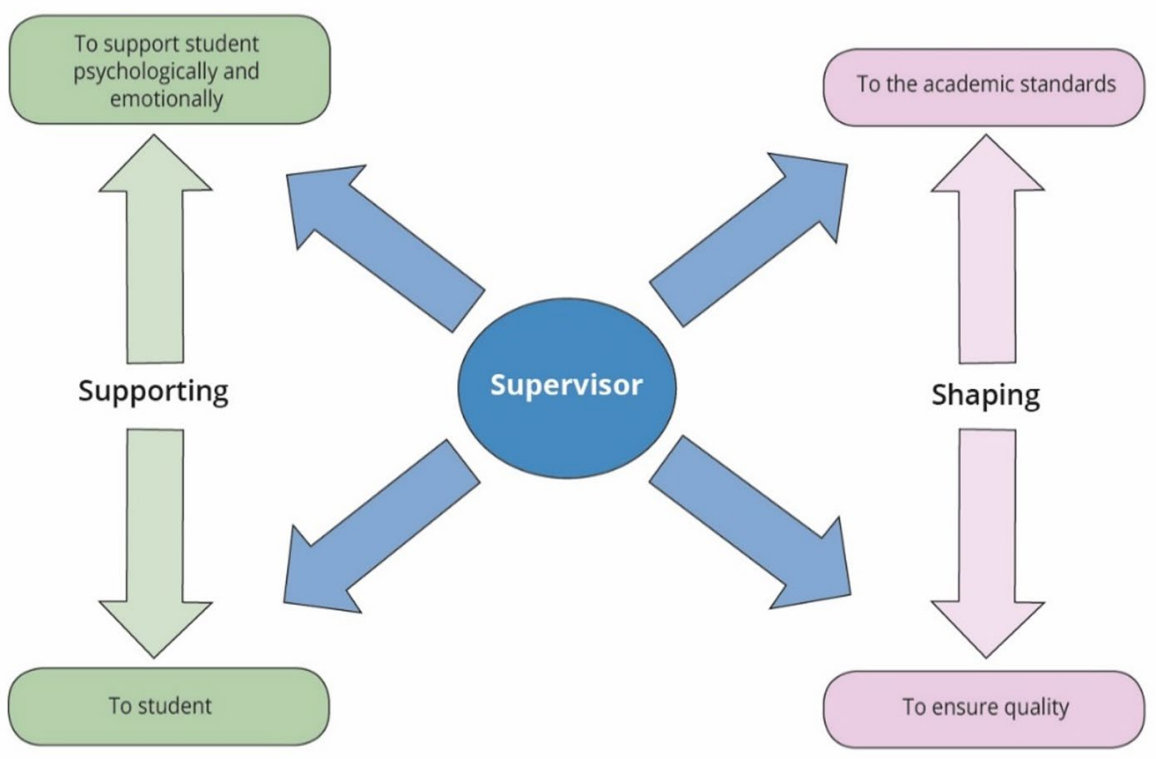

Figure 1: The duality of shaping and supporting in supervision (Adapted from Anderson et al. 2006, 164)

\section{Experimentation of new roles}

At first, I wanted to replace my one-on-one supervision practice with an alternative method. However, in reviewing the value of one-on-one supervision, I agree with Bitzer and Albertyn (2011), who mention that despite the inherent shortcomings of the single supervisor approach, one should not dismiss this structure of supervision as having no value. De Lange, Pillay and Chikoko (2011) also mention that an individual supervision approach should not be replaced on the basis of the complexity of the supervision task; however, it does need to be complemented by other strategies. Between 2007 and 2014 I experimented with various formats of group supervision (see Figure 2).

\section{A new integrated perspective on supervision}

My supervision evolved into a mix of solo and small-group supervision sessions, where the groups were informal, diverse and relied heavily on student reflections for learning (O'Neil et al. 2016). My perspective shifted from originally relying on directive, solo supervision to more indirective, solo and group supervision. Upon reflection I realised that even though I was more experienced than students in terms of my research capability, students themselves could guide each other during the group supervision processes. The addition of group supervision with solo supervision proved to work well for both my students and myself (see O'Neil et al. 2016). 


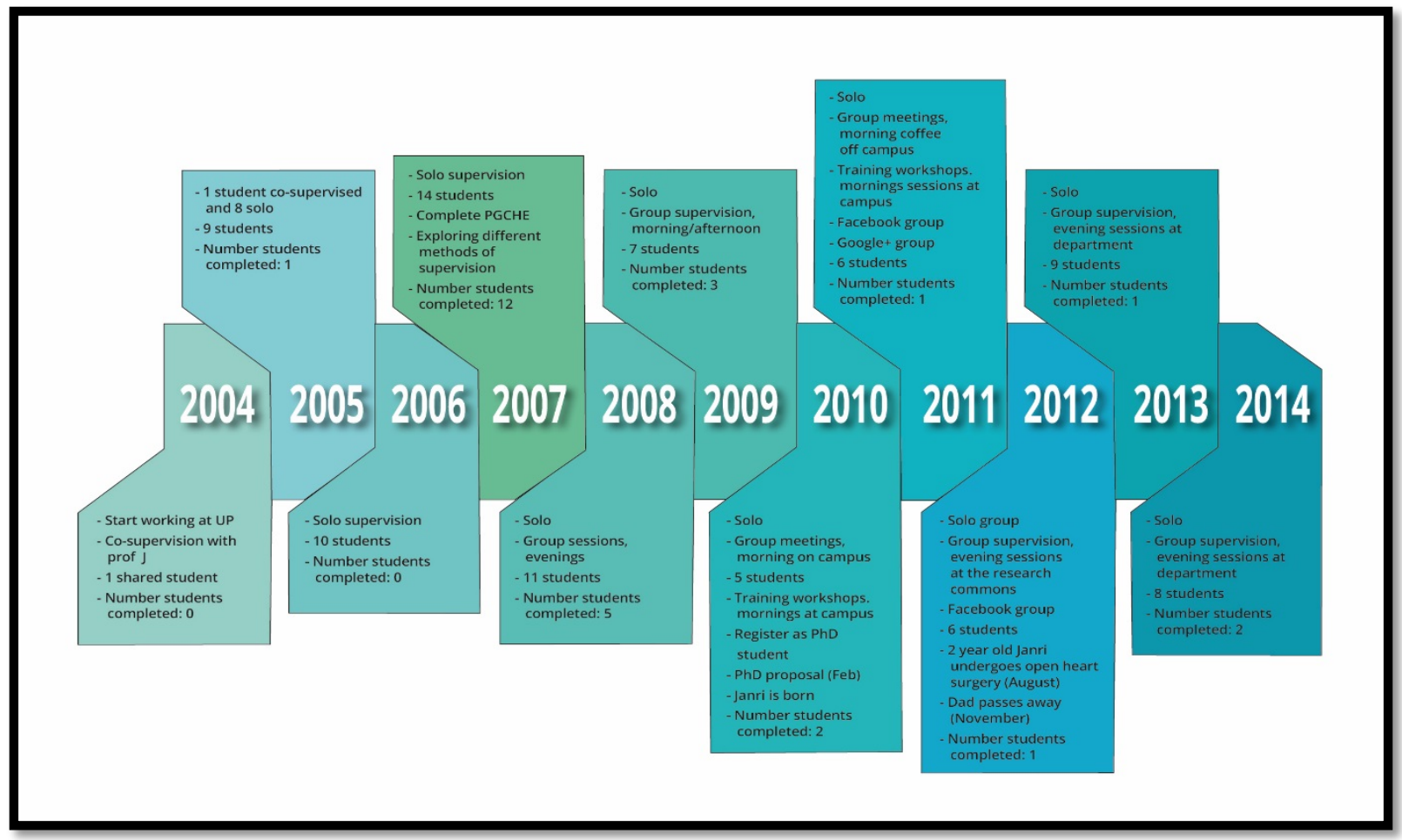

Figure 2: My supervision timeline (2004-2014) used to reflect on different supervision practices and experiences during my autoethnographic study (O’Neil 2016, 258)

\section{THE FEATURES OF AUTOETHNOGRAPHY THAT FACILITATE PROFESSIONAL DEVELOPMENT}

It is evident from the preceding section that practice-based insider research such as autoethnography does not only help the practitioner gain knowledge about his or her professional practice, but also aids in changing the practice (Boucher and Smyth 2004). The previous section illustrated the process of transformation in my perspectives on supervision by juxtaposing the process of my development through autoethnography to Mezirow's process of transformative learning. In reflection on this process, it is evident that autoethnography as a method is suitable to be used as a tool in professional development because of inherent qualities that lends itself to reflection and learning in context, namely, providing in-context learning opportunities and being inherently reflective.

\section{Autoethnography provides in-context learning opportunities}

One of the major critiques against most professional development methods are that they do not take into account the individual's context. Learning without contextual understanding often leads to knowledge that does not transform practice. Dirkx (1998) notes that for transformative learning to take place one should have a full understanding of one's personal situation as well as the context in which one lives. Being rooted in ethnography, autoethnography is more than 
a mere reflection on one's own practice. The method advocates a focus on the culture and context in which the story takes place (Wall 2006). The introspective and retrospective stance of autoethnography enhances understanding of the relationship between the organisation (context) and the individual (Boyle and Parry 2007; Parry 2008).

Context in autoethnography is provided by including conversations with peers as well as analysing one's personal story within the context in which it is studied. As part of the methodology of analytic autoethnography, Anderson (2006) refers to inquiry from peers as part of the data collection process. For my study, I relied on informal interviews with five of my colleagues who also supervise master's mini-dissertation students. This provided "hard" data (Chang 2008). However, I gained most of the information from colleagues from informal discussions in the hallways and tea-room chats over our supervision practices, the barriers we face, and the solutions we found. This also allowed me to see the relationship between my own practices and the context, which includes the institutional culture and demands, and the needs of the student, as well as my personal context (i.e. being a mother, daughter and wife) (Wall 2006).

Even for methodologies embracing constructivist world-views, using informal avenues such as tearoom chatter may put the integrity of a study at risk. Autoethnography, however, embraces the use of informal conversations and observations as part of the data collection. It facilitates one's understanding of context and culture. For me, it led in a sense to social informal learning about supervision within the context of the specific institution at which I was situated. Gerken, Beausaert and Segers (2016) discuss the potential of social informal learning (in activities such as discussions with colleagues, or observing others in the workplace) in organisations for professional development. Instead of relying on in-service training activities that are outside the day-to-day tasks of an academic, social informal learning will help professional development to take place within the work context. This contextualisation of learning improves one's understanding of your own practices. For example, because autoethnography is contextualised in daily work activities, it led me to the realisation of the deep rootedness of one's supervisory decisions. I found that supervision of master's coursework students has some unique challenges that are amplified by factors related to the landscape of higher education in South Africa:

"The culture of the institution is embedded in the higher education landscape of the country, while the expectations of higher education in the country are influenced by the trends in higher education globally. For instance, decreased funding to the institution may lead to increased student numbers and a decrease in staff numbers. This in turn places a greater burden on supervising staff members in terms of their workload in general as well as the number of students they have to supervise. In 
view of the considerations related to saving time and effort during supervision, together with the mini-dissertation students' expectations and efforts to save their reputation (during external examination), supervisors will give an abundance of structure or rewrite sections in the minidissertation. Decisions made with regard to supervision practices rarely focus on student learning, instead favouring shortened completion times and publication possibilities for supervisors. This leads to functionalist approaches to supervision which are not optimal to research learning." (Excerpt from my autoethnography) (O’Neil 2016, 260).

\section{Autoethnography is grounded in critical reflection}

Critical reflection on one's own practice is an important component in professional development (Panda 2004). Autoethnography offers a good method for professional development as it is by nature self-reflective and focussed on own practice. For transformative learning to occur, critical reflection and critical dialogues form part of the process of uncovering one's tacit assumptions (Hoggan 2016). Accordingly, learning takes place from a social constructivist perspective.

\section{Autoethnography is inherently creative}

Apart from critical dialogues and reflection, Dirkx (1998) mentions that imagination and creativity also play a key role in transformative learning. As a methodology, autoethnography is grounded in cycles of reflection on action to facilitate an understanding of one's own story as well as the context in which it takes place. In the process of writing or displaying (i.e. visual or arts-based representations) and research, there is a display of "multiple layers of consciousness" (Ellis and Bochner 2000, 733). The story that one creates after data collection becomes data in itself. In the words of Richardson (2000, 254): "Self-reflexivity brings to consciousness some of the complex political/ideological agendas hidden in our writing." I experienced this first hand during my autoethnographic journey:

"When I started writing, I found that the pieces that I wrote actually stood out as data too. See, I wrote stories to depict the culture of the University and my life and so forth ... and from writing the stories I came to new realisations - as one would from new data. Yet it was already in the written-up format." (O’Neil 2016, 111).

In autoethnography, writing is a form of inquiry or a form of knowing: "By writing in different ways, we discover new aspects of our topic and our relationship to it" (Wall 2006, 6). Similarly, Boyd (2008) notes that it is in this process of active reflection through writing that often the invisible becomes visible and the tacit becomes conscious.

Although descriptive-realistic and analytic-interpretive writings are used more often in analytic autoethnography (Ngunjiri, Hernandez and Chang 2010), analytic autoethnographers 
do not exclude creative and first-person writings (Chang 2008). Vryan (2006) argues that the intense self-immersion and reflection that can lead to discoveries may represent the advantage of autoethnography over other forms of social research. Blending the analytic and the evocative in this way is an integration of the clarity of modernism and the honesty and completeness of postmodernism (Blumenthal 1999).

CAP taps into what Dirkx (2008) refers to as "soul work", which suggests that perspective transformation is more than a mere cognitive process. Perspective transformation also implies an emotional process which in autoethnography often becomes visible in the creative displays of experiences (Haynes 2011).

\section{FINAL REMARKS}

Autoethnography is not without limitations. Firstly, the method may take more time than there is available for professional development. Kinchin and Cabot (2015) used concept mapping to focus the reflections in their framed autoethnographic method. For analytic autoethnography one may use methods such as timelines and focussed reflections through self-interviewing (Chang 2008) to focus reflections on specific workplace experiences. A second limitation may be a lack of skill to employ autoethnographic methods. I found my limited writing capability to be a challenge in completing my autoethnography. Others may find their lack of research methodology skills to be a challenge.

The strength of autoethnography for the use of professional development lies in its transformative nature (Blalock and Akehi 2017). De Rijdt et al. (2013) note that one of the shortcomings of professional development efforts is that transfer of learning to the workplace is difficult. Accordingly, studies in the field of professional development rarely note the actual changes that occur in the workplace.

In this article, I have shared my personal experience of using analytic autoethnography to find a solution to dilemmas I faced in my supervision practice. The journey led to a transformative learning experience, through which change was brought about not only in how I ascribe meaning to being a postgraduate research supervisor, but also in my supervision practice. By analysing this experience through the lens of transformative learning theory I could illustrate how analytic autoethnography can be used within a supervisor's professional development process.

\section{REFERENCES}

Adams, T. E., Jones S. Holman and C. Ellis. 2015. Autoethnography: Understanding qualitative research. New York: Oxford University Press. 
Anderson, L. and B. Glass-Coffin. 2013. "I learn by going: Autoethnographic modes of inquiry". In Handbook of autoethnography, ed. S. Holman Jones, T. E. Adams and C. Ellis, 57-83. Walnut Creek, CA: Left Coast Press.

Anderson, L. 2006. Analytic autoethnography. Journal of Contemporary Ethnography 35: 373-395. doi:10.1177/0891241605280449.

Anderson, C., K. Day and P. McLaughlin. 2006. Mastering the dissertation: Lecturers' representations of the purposes and processes of master's level dissertation supervision. Studies in Higher Education 31(2): 149-168. doi: 10.1080/03075070600572017.

Becker, A. L. 2017. Personal transformation in RNs who recently graduated from an RN to BSN program. Journal of Transformative Education 15(4): 315-333.

Behari-Leak, K. 2017. New academics, new higher education contexts: A critical perspective on professional development. Teaching in Higher Education 22(5): 485-500. doi:10.1080/13562517.2016.1273215.

Bitzer, E. and R. M. Albertyn. 2011. Alternative approaches to post-graduate supervision: A planning tool to facilitate supervisory processes. South African Journal of Higher Education 25(5): 874888.

Blalock, A. E. and M. Akehi. 2017. Collaborative autoethnography as a pathway for transformative learning. Journal of Transformative Education: 1541344617715711.

Blumenthal, D. 1999. Representing the divided self. Qualitative Inquiry 5(3): 377-392. doi:10.1177/107780049900500305.

Botha, N. 2010. Practices in post-graduate research supervision: From apprentice to scholar. Acta Academica Supplementum 1: 57-74.

Boucher, C. and A. Smyth. 2004. Up close and personal: Reflections on our experience of supervising research candidates who are using personal reflective techniques. Reflective Practice 5(3): 345 356. doi:10/1080.1462394042000270664.

Boyd, D. 2008. Autoethnography as a tool for transformative learning about white privilege. Journal of Transformative Education 6(3): 212-225. doi:10.1177/1541344608326899.

Boyle, M. and K. Parry. 2007. Telling the whole story: A case for organizational autoethnography. Culture and Organizations 13(3): 185-190.

Chang, H. 2008. Autoethnography as method. Walnut Creek, CA: Left Coast Press.

Chang, H., K. A. Longman and M. A. Franco. 2014. Leadership development through mentoring in Higher Education: A collaborative autoethnography of leaders of color. Mentoring and Tutoring: Partnership in Learning 22(4): 373-389.

Chang, H., F. W. Ngunjiri and K. A. Hernandez. 2013. Collaborative autoethnography. CA: Walnut Creek: Left Coast Press.

Conrad, L. 2003. Five ways of enhancing the post-graduate community: Student perceptions of effective supervision and support. Paper presented at the Actas de la Confrencia Annual. https://www.herdsa.org.au (Accessed 2 February 2008).

Cunningham, S. J. and M. Jones. 2005. Autoethnography: A tool for practice and education. In Proceedings of the 6th ACM SIGCHI New Zealand chapter's international conference on Computer-human interaction: Making CHI natural, 1-8. ACM.

De Lange, N., G. Pillay and V. Chikoko. 2011. Doctoral learning: A case for a cohort model of supervision and support. South African Journal of Education 31: 15-31.

De Rijdt, C., A. Stes, C. Van der Vleuten and F. Dochy. 2013. Influencing variables and moderators of transfer of learning to the workplace within the area of staff development in higher education: Research review. Educational Research Review 8: 48-74.

DeBerry-Spence, B. 2010. Making theory and practice in subsistence markets: An analytical autoethnography of MASAZI in Accra, Ghana. Journal of Business Research 63(6): 608-616.

Dewey, J. 1933. How we think: A restatement of the relation of reflective thinking to the educative 
process. Health 35: 64. Lexington, MA.

Dirkx, J. M. 1998. Transformative learning theory in practice of adult education: An overview. PAACE Journal of Lifelong Learning 7: 1-14.

Dirkx, J. M. 2008. The meaning and role of emotions in adult learning. New Directions for Adult and Continuing Education (120): 7-18.

Duncan, M. 2004. Autoethnography: Critical appreciation of an emerging art. International Journal of Qualitative Methods 3(4).

Ellis, C. and A. P. Bochner. 2000. Autoethnography, personal narrative, reflexivity: Researcher as subject. In Handbook of qualitative research, ed. N. K. Denzin and Y. S. Lincoln, 733-768. $2^{\text {nd }}$ Edition. Thousand Oaks, CA: Sage.

Ellis, C. and J. Rawicki. 2013. Collaborative witnessing of survival during the holocaust: An exemplar of relational autoethnography. Qualitative Inquiry 19(5): 366-380. doi:10.1177/ 1077800413479562.

Gearity, B. T. and N. Mertz. 2012. From "bitch" to "mentor": A doctoral student's story of self-change and mentoring. The Qualitative Report 17(30): 1.

Gerken, M., S. Beausaert and M. Segers. 2016. Working on professional development of faculty staff in higher education: Investigating the relationship between social informal learning activities and employability. Human Resource Development International 19(2): 135-151. doi:10.1080/ 13678868.20015.1116241.

Grenier, R. S. and J. C. Collins. 2016. "Man, have I got a story for you": Facilitated autoethnography as a potential research methodology in human resource development. Human Resource Development Review 15(3): 359-376. doi:10.1177/1534484316656658.

Habermas, J. 1971. Knowledge and human interests. Boston: Beacon.

Hayano, D. 1979. Auto-ethnography: Paradigms, problems, and prospects. Human Organization 38(1): 99-104.

Haynes, K. 2011. Tensions in (re)presenting the self in reflexive autoethnographical research. Qualitative Research in Organizations and Management: An International Journal 6(2): 134-149. doi:10.1108/17645641111159125.

Hoggan, C. D. 2016. Transformative learning as a metatheory: Definition, criteria, and typology. Adult Education Quarterly 66(1): 57-75.

Holt, N. L. 2003. Representation, legitimation, and autoethnography: An autoethnographic writing story. International Journal of Qualitative Methods 2(1): Article 2.

Karra, N. and N. Phillips. 2008. Researching "back home". Organizational Research Methods 11(3): 541-561. doi:10.117/1094428106295496.

Kempster, S. and M. Iszatt-White. 2012. Towards co-constructed coaching: Exploring the integration of coaching and co-constructed autoethnography in leadership development. Management Learning 0(0): 1-18. doi:10.1177/1350507612449959.

Kennedy, A. 2005. Models of continuing professional development: A framework for analysis. Journal of In-service Education 31(2): 235-249.

Kinchin, I. M. and L. B. Cabot. 2015. Framed autoethnography as an approach for uncovering pedagogic frailty. Contemporary Educational Researchers Journal 6(1): 40-47.

Lauer, P. A., D. E. Christopher, R. Firpo-Triplett and F. Buchting. 2014. The impact of short-term professional development on participant outcomes: A review of the literature. Professional Development in Education 40: 207-227.

Learmonth, M. and M. Humphreys. 2011. Autoethnography and academic identity: Glimpsing business school doppelgängers. Organization 19(1): 99-117. doi:10.1177/1350508411398056.

Lee, A. and B. Green. 2009. Supervision as metaphor. Studies in Higher Education 34(6): 615-630. doi:10.1080/03075070802597168. 
Lueddeke, G. R. 2003. Professionalising teaching practice in higher education: A study of disciplinary variation and "teaching scholarship". Studies in Higher Education 2: 213-228.

McIlveen, P., G. Beccaria, J. du Preez and W. Patton. 2010. Autoethnography in vocational psychology: Wearing your class on your sleeve. Journal of Career Development 37(3): 599-615.

McNiff, J. 1995. Action research for professional development. Bournemouth: Hyde Publications.

Mezirow, J. 1991. Transformative dimensions in adult learning. San Francisco: Jossey-Bass.

Mezirow, J. 1996. Contemporary paradigms of learning. Adult Education Quarterly 46(3): 158-172.

Mezirow, J. 1997. "Transformative learning: Theory to practice". In Transformative learning in action: Insights from practice - New directions for adult and continuing education, ed. P. Cranton, (74): 5-12. San Francisco: Jossey-Bass.

Mezirow, J. 2000. Learning as transformation: Critical perspectives on a theory in progress. San Francisco: Jossey-Bass.

Moon, J. A. 1999. Learning journals: A handbook for academics, students and professional development. Routledge.

Muncey, T. 2005. Doing autoethnography. International Journal of Qualitative Methods 4(1): 69-86.

Mulà, I., D. Tilbury, A. Ryan, M. Mader, J. Dlouhà, C. Mader, J. Bynayas, J. Dlouhý and D. Alba. 2017. Catalysing change in higher education for sustainable development: A review of professional development initiatives for university educators. International Journal of Sustainability in Higher Education 18(5): 792-820.

Ngunjiri, F. W., K. C. Hernandez and H. Chang. 2010. Living autoethnography: Connecting life and research. Journal of Research Practice 6(1): Article E1. http://jrp.icaap.org/index.php/jrp/ article/view/241/186 (Accessed 4 February 2012).

O’Neil, S. M. 2016. Constructing a more effective postgraduate research supervision practice: An autoethnography. PhD dissertation. Pretoria: University of Pretoria.

O'Neil, S. M., W. Schurink and K. Stanz. 2016. The benefits of using small supervisor-initiated groups to supervise master's research. South African Journal of Higher Education 30(4): 210-230.

Panda, S. 2004. Reflection and continuing professional development: Implications for online distance learning. Indian Journal of Open Learning 13(1): 63-77

Parry, K. W. 2008. Viewing the leadership narrative through alternative lenses: An autoethnographic investigation. Management Review 19(1/2): 126-147. http://hdl.handle.net/10419/79044

Pelias, R. J. 2003. The academic tourist: An autoethnography. Qualitative Inquiry 9(3): 369-373. doi:10.1177/1077800403009003003.

Rawicki, J. and C. Ellis. 2010. Survival and sacrifice during the Holocaust. Qualitative Inquiry 17(2): 155-157. doi:10.1177/1077800410392337.

Richardson, L. 2000. New writing practices in qualitative research. Sociology of Sport Journal 17(1): $5-20$.

Schön, D. 1983. The reflective practitioner. London: Maurice Temple Smith Ltd.

Sergi, V. and A. Hallin. 2011. Thick performances, not just thick descriptions: The processual nature of doing qualitative research. Qualitative Research in Organizations and Management: An International Journal 6(2): 191-208.

Sprow Forte, K. and D. Blouin. 2016. Fostering transformative learning in an online ESL professional development program for K-12 teachers. The Qualitative Report 21(4): 781-797.

Tillman, L. M. 2011. Labor pains in the academy. Cultural Studies, Critical Methodologies 11(2): 195198. doi:10.1177/1532708611401338.

Van Amsterdam, N. 2014. Othering the "leaky body": An autoethnographic story about expressing breast milk in the workplace. Culture and Organization 21(3): 1-19. doi:10.1080/14759551.2014.887081. 
Vilkinas, T., 2002. The PhD process: The supervisor as manager. Education + Training 44(3): 129137.

Vryan, K. D. 2006. Expanding analytic autoethnography and enhancing its potential. Journal of Contemporary Ethnography 35: 405. doi:10.1177/0891241606286977.

Wall, S. 2006. An autoethnography on learning about autoethnography. International Journal of Qualitative Methods 5(2): Article 9.

Willig, C. 2013. Introducing qualitative research in psychology. $3^{\text {rd }}$ Edition. Berkshire, UK: McGrawHill Education. 